\title{
MÉTODOS DE CUSTEIO NA ADMINISTRAÇÃO PÚBLICA: ESTUDO DE CASO NA POLÍCIA MILITAR DE SANTA CATARINA (PMSC)
}

\author{
Jacqueline Benta Ferreira ${ }^{1}$, Sérgio Murilo Petri ${ }^{2}$ \\ 1,2 Universidade Federal de Santa Catarina \\ 1jacqueline.benta95@gmail.com \\ ${ }^{2}$ sergio.petridufsc.br
}

\section{Resumo}

O objetivo verificar o método de custeio adequado que contribua no processo de apoio à tomada de decisão na Polícia Militar de Santa Catarina (PMSC). Assim, o estudo os métodos de custeio que podem ser utilizados no setor público. Trata-se de uma pesquisa descritiva, documental, qualitativa e um estudo de caso. Com a propósito de analisar os sistemas de custeio e focalizar em alguns métodos de custeio, como custeio padrão, custeio direto ou variável, custeio por absorção e o custeio por atividade (ABC), assim apoiando o processo de tomada de decisão deste órgão público. Apurando assim que cada método de custeio fornece uma determinada informação, como também suas vantagens e desvantagens, e permitindo a apuração dos seus custos tanto totais como unitários. $\mathrm{Na}$ analise dos resultados aponta ser mais adequado à aplicação do método de custeio por absorção, pois identifica os custos de cada bem ou serviço produzido pela organização e tem o melhor custo-benefício, isto é, pouco custoso com relação aos demais e como é uma organização de grande porte necessita saber detalhadamente de onde vêm os determinados custos. Como resultado da pesquisa, a diferença entre os anos analisados pelo método de custeio por absorção, diminuiu em duzentos e cinquenta reais e trinta e três centavos de 2014 para 2015; e em setenta e quatro reais e vinte e seis centavos de 2015 para 2016. Somando uma diminuição de trezentos e vinte e quatro reais e cinquenta e nove centavos do primeiro (2014) para o último ano (2016). Analisando até julho de 2017, houve uma diminuição em cinquenta e seis reais e sessenta e um centavos de 2016 para julho/2017. O método adequado por meio das análises dos resultados indicou que o método de custeio por absorção é o mais adéquo para tomada de decisão deste órgão público.

Palavras Chave: Administração Pública. Métodos de Custeio. Sistemas de Informação de Custo.

\section{METHODS OF COST IN THE PUBLIC ADMINISTRATION: CASE STUDY IN THE MILITARY POLICE OF SANTA CATARINA (MPSC)}

\section{Abstract}

The objective is to verify the adequate costing method that contributes to the decision support process in the Military Police of Santa Catarina (PMSC). Thus, the study costing methods that can be used in the public sector. It is a descriptive, documentary, qualitative research and a case study. With the purpose of analyzing the costing systems and focusing on some costing methods, such as standard costing, direct or variable costing, absorption costing and costing by activity $(A B C)$, thus supporting the decision making process of this public agency. Thus, each costing method provides information, as well as its advantages and disadvantages, and allows the calculation of its total and unit costs. In the analysis of the results, it is more 
appropriate to apply the absorptive costing method, since it identifies the costs of each good or service produced by the organization and is the most cost-effective, that is, little costly in relation to the others and how it is a organization needs to know in detail where the costs come from. As a result of the survey, the difference between the years analyzed by the absorption cost method decreased by two hundred and fifty reais and thirty-three cents from 2014 to 2015; and seventy-four reais and twenty-six cents from 2015 to 2016. Adding a decrease of three hundred and twenty-four reais and fifty-nine cents from the first (2014) to the last year (2016). Analyzing until July 2017, there was a decrease in fifty-six reais and sixty-one cents in 2016 to July / 2017. The appropriate method through the analysis of the results indicated that the absorption costing method is the most suitable for decision making of this public body.

Keywords: Public Administration. Costing Methods. Cost Information Systems.

\section{Introdução}

No Brasil, em meados de 1995, ocorreu a implantação da reforma gerencial que foi inspirada no modelo britânico, que seria a New Public Management (NPM - Nova Gestão Pública). Assim, com essa implantação, a NPM procurou adquirir um novo padrão de gestão pública, a nomeada "administração gerencial", que vem sendo apoiado nos princípios da maleabilidade, foco nos resultados e ênfase nos controles sociais e nos clientes. (WEIL, 2005).

Existem mecanismos legais para apurar os custos na administração pública, como evidencia a eficácia, eficiência e transparência. Além desses aspectos legais, pode-se destacar o valor da informação de custos para fins gerenciais. Seu destaque para o interesse no setor público pode ser compreendida pela influencia que tem na gestão pública, seja pela sua qualidade útil ou por sua perspectiva legal Abel e Eberly, (1999); Kinney (2003); Sardar, Ramachandran e Gopinath (2006); Luporini e Alves (2010); Carmo e Silva (2011); West ( 2016).

Segundo o Art. 99 da Lei Federal N4.320, de 17 de março de 1964, determina que "Os serviços públicos [...] manterão contabilidade especial para determinação dos custos, ingressos e resultados, sem prejuízo da escrituração patrimonial e financeira comum”.

O Manual de Contabilidade Aplicada ao Setor Pública (7º Edição - 2017) pretende contribuir com o método de elaboração e execução do orçamento, além de ajudar a resgatar o objeto da Contabilidade como Ciência, que é o patrimônio. Com isso, a Contabilidade será capaz de atender a demanda de informações solicitadas por seus usuários, proporcionando a análise de demonstrações contábeis apropriadas aos padrões internacionais, perante os enfoques patrimoniais e orçamentários, com apoio do Plano de Contas Nacional.

As normas estabelecidas pelo MCASP aprofundam-se, obrigatoriamente, às entidades do setor público. São eles: os governos nacional (união), estaduais, distrital (Distrito Federal) e municipais e seus respectivos poderes (abrangidos os tribunais de contas, as defensorias e o Ministério Público), órgãos, secretarias, departamentos, agências, autarquias, fundações (instituídas e mantidas pelo poder público), fundos, consórcios públicos e outras repartições públicas congêneres das administrações direta e indireta, inclusive as empresas estatais dependentes (MCAPS, $7^{\circ}$ Edição, 2017).

Para Carmo e Silva (2011) e West (2016).) uma das funções mais relevantes é a tomada de decisão, sendo um papel de muita importância, "pois consiste na alimentação de informações sobre valores relevantes que dizem respeito às consequências de curto e longo prazo sobre medidas de introdução".

Neste sentido Machado e Holanda (2010) descrevem que para o setor público há uma complexidade na escolha do método de custeio, considerando que há defensores para quase 
todos os tipos de métodos, assim sendo eficaz a adoção de qualquer um dos cincos métodos. Já no setor privado, há uma limitação legal quanto ao uso dos métodos de custeio.

A partir do conteúdo desta contextualização surge o seguinte problema de pesquisa: Qual método de custeio é adequado para contribuir no processo de apoio à tomada de decisão na Polícia Militar do Estado de Santa Catarina (PMSC)?

O objetivo desta pesquisa é verificar o método de custeio adequado que contribua no processo de tomada de decisão na Polícia Militar do Estado de Santa Catarina (PMSC).

A premissa deste estudo tem como importância a implantação de métodos de custos que dê um suporte na administração pública de forma eficaz e eficiente. Assim, tendo como essência a identificação da contribuição de cada um dos métodos de custeio no processo de tomada de decisão na gestão pública, de acordo com estudos Rothschild (1971); Noreen e Soderstrom, (1997); Peter (2001); Harris e Carapiet, (2006); Banker, Fang e Mehta, M (2012); Porporato e Werbin (2012); Banker, byzalov, Chen (2013); Banker, Byzalov e Plehn-Dujowich, (2014); Martins e Rosa (2014); Novák e Vencálek (2016).

O artigo está constituído em cinco capítulos. No primeiro, descreveu-se o problema da pesquisa. No segundo, efetuou-se a revisão na literatura, abordando os métodos de custeio na administração pública. Na sequência, foram tratados os procedimentos metodológicos. Depois, o estudo de caso da Polícia Militar de Santa Catarina (PMSC) e a análise dos resultados, e por fim, as considerações finais da pesquisa.

\section{Revisão da literatura}

Com a intenção de chegar ao objetivo do estudo, a revisão da literatura apresenta temas referentes a sistemas de custos e métodos de custeio na administração pública.

\subsection{Sistema de Informação de Custos}

Ao referir-se a necessidade de apuração de custos na administração pública brasileira Alonso (1999) destaca que a partir da década de 80, com o aumento da crise fiscal pela qual o Estado estava passando, agregado à exposição dos mercados domésticos à competição internacional, assim forçando estes a reorientarem a sua política econômica com intuito de conter suas despesas.

Para dispor do sistema de custos é fundamental abordar o entendimento de Machado (2002) que ao longo do tempo, os termos sistemas de custos, sistema de custeio, método de custeio e técnica de custeio, entre outros, têm sido descritos na literatura contábil com significados distintos ou similares, dependendo do autor, do objetivo e do momento em que aparecem.

Silva (2007) classifica a contabilidade de custos no setor público como pilar de apoio ao processo decisório que auxilia os gestores em:

a) decidir entre produzir e prestar serviços ou terceirizar sua execução;

b) calcular e justificar o valor das taxas e preços públicos a serem cobrados;

c) facilitar a elaboração dos orçamentos;

d) medir a eficiência, eficácia, economia, sub-atividades ou sobreatividades;

e) fundamentar o valor dos bens produzidos pelo órgão para uso próprio ou bens de uso comum do povo;

f) apoiar decisões sobre continuar responsável pela produção de determinado bem, serviço ou atividade ou entregar a entidades externas;

g) facilitar informação a entidades financiadoras de produtos serviços ou atividades;

h) comparar custos de produtos ou serviços similares entre diferentes órgãos do setor público; 
i) determinar o valor pelo qual deve ser registrado contabilmente um ativo que está sendo produzido pela própria administração.

Desse modo, fica claro que o sistema de informação está estreitamente ligado a contabilidade e ressalta a importância de ser um sistema que proporciona benefícios à Administração Pública. Para enfatizar o contexto Alonso (1999) determina que a apuração e sua divulgação dos custos no setor público exerceriam papel de importantes instrumentos de controle social, por permitir a auditoria e aos usuários a avaliação de eficiência dos serviços prestados.

O sistema de custos oferece como objetivo informações internas. Segundo Hansen e Mowen (2001) ela possui três objetivos: a) fornecer informações para computar o custo dos serviços, produtos e outros objetos de interesse da gestão; b) fornecer informações para o planejamento e controle; c) fornecer informações para a tomada de decisão.

Segundo Martinez e Alves (2011) o sistema de custo tem como finalidade dotar a administração pública de meios que permitam a apuração, o gerenciamento e apropriação dos custos aos elementos de custeio, assim deverá organizar relatórios gerenciais para poder atender as necessidades dos diversos gestores, tornando transparente a aplicação dos recursos públicos.

Conforme Machado e Holanda (2010) o sucesso da implantação do Sistema de Informação de Custos nos entes públicos não depende apenas da estrutura conceitual nem da exigência legal, apesar desses fatores serem fundamentais, a sua importância está na utilização das informações de custos para o melhoramento gerencial e controle de suas atividades e no aprimoramento do processo de decisão.

A principal função dos governos e de outras entidades no setor público é o fornecimento de serviços que possam aprimorar ou manter o bem-estar dos cidadãos e dos outros indivíduos (NBCTSPEC, 2016

O sistema de informação de custos é um depósito de dados digitais que serve para armazenar informações detalhadas da administração pública, tal como o Sistema Integrado de Administração de Recursos Humanos (SIAPE), Sistema Integrado de Administração Financeira do Governo Federal (SIAFI) e Sistema de Informações Gerenciais e de Planejamento do Plano Plurianual (SIGPlan). Tem por objetivo auxiliar nas decisões dos governos e das organizações que conduzam à alocação mais eficiente do gasto público, sendo importante para a alteração de modelos que existem atualmente na visão estratégica do papel do setor público (STN, 2012).

A Secretaria de Tesouro Nacional (2012) em 09 de março de 2011, a Portaria $\mathrm{n}^{\circ} 157$ criou o Sistema de Custos do Governo Federal, organizado de uma forma de um subsistema organizacional da administração pública federal brasileira e vinculado ao sistema de Contabilidade Federal, visto que se encontra sob gestão da Coordenação-Geral de Contabilidade e Custos da União. Considerando sua existência, ela obriga a Administração Pública a manter sistema de custos que permita a avaliação e o acompanhamento da gestão orçamentária, financeira e patrimonial; e organiza e disciplina o Sistema de Contabilidade Federal do Poder Executivo, pertencendo as respectivas leis, ao art. 50, $\S 3^{\circ}$ da Lei Complementar $\mathrm{n}^{\mathrm{o}}$ 101, de 04 de maio de 2000 - Lei de Responsabilidade Fiscal (LRF) e a Lei $\mathrm{n}^{\mathrm{o}} 10.180$, de 06 de fevereiro de 2001.

Para Weil, (2005) o sistema de custos oferece informações econômicas para a tomada de decisções estratégicas e operacionais. Trata-se de uma das mais intensas estratégicas empresariais dos últimos anos, por meio da qual as companhias avaliam iniciativas de qualidade, cortam desperdícios, melhoram serviços, impulsionam para o melhoramento contínuo e calculam, com adequada precisão, os custos dos produtos. 


\subsection{Apuração do Sistema de Custos no Setor Público}

Observada a obrigação da implantação de um sistema de informação que estime os custos no setor público, surge à questão de qual o melhor método de custeio para ser implantado. Inúmeros estudos fundamentam uma adoção para um determinado método, sendo levantados aplicações e fundamentos, o que será demonstrado. Em seguida, serão apresentados os métodos de custos, assim como seus embasamentos e aplicações no setor público.

\subsection{Métodos de Custeio}

Método de custeio se considera um método de apropriação de custos e está agregado ao processo de identificação e associado do custo ao objeto que está sendo custeado. Os principais métodos de custeio são: custo padrão, por absorção, direto ou variável e por atividade (ABC).

Segundo Machado e Holanda (2010) não é fácil à escolha do método de custeio do setor público, pois há defensores para quase todos os métodos. Além de que, no setor público há limitações legais quanto ao uso dos métodos de custeio, podendo assim utilizar qualquer um dos métodos, diferente do setor privado que há limitações.

Os motivos legais não determinam qual o determinado método de custeio que tem que ser seguido, somente regulamentam sobre a implantação do sistema no setor público. Assim, qualquer um dos métodos destacados neste estudo pode ser considerado, manifestando assim com diversas discussões sobre qual seria o melhor método de custeio a ser adotado no setor público no sistema de informação de custos.

\subsubsection{Custeio Padrão}

Segundo Mauss e Souza (2008) se manifestam favorável a utilização do custo-padrão como elemento que serve de base para a comparação do que fora planejado com os bens ou serviços produzidos. Ressaltam que este método precisaria ajustar-se como apoio para elaboração do orçamento público, fornecendo os limites de gastos, não podendo ser aplicado para apuração dos custos.

Quadro 1 - Vantagens e Desvantagens do Custeio Padrão.

\begin{tabular}{|l|l|}
\hline \multicolumn{1}{|c|}{ VANTAGENS } & \multicolumn{1}{|c|}{ DESVANTAGENS } \\
\hline - É praticamente o único adequado em empresas que & - Imputar linearmente as variações a todos os produtos, \\
produzem, sem série, centenas de artigos diferentes, & quando as apropria em base percentual; \\
especialmente se a matéria-prima for comum a todos eles; & - Todos os produtos sofrem uma carga percentual das \\
- Apuração de um custo real exigirá o controle de & variações, já que o sistema não permite identificar os \\
identificação da matéria-prima consumida em cada & produtos em cuja fabricação ocorreram deficiências de \\
produto (tempo de fabricação por centro de custos e & $\begin{array}{l}\text { aproveitamento de materiais e ineficiência de mão de obra } \\
\text { sem um esforço muito grande; }\end{array}$ \\
produtos); & - É possível uma comparação direta entre as despesas por \\
análise desde que possa extrair uma variação entre o & natureza computada na elaboração do custo-padrão e \\
custo-padrão (normal) e o custo real. & aquelas efetivamente incorridas durante o período. \\
\hline
\end{tabular}

FONTE: adaptado de Weil, (2005) e MARTINS e ROSA (2014),

Hansen e Mowen (2009) o custeio padrão tem suas vantagens sobre o custeio normal e o custeio real, que é a sua capacidade maior de controla. Os sistemas de custo padrão também fornecem informações imediatamente disponíveis sobre o custo unitário que pode ser usado para determinar decisões. 


\subsubsection{Custeio Direto ou Variável}

Segundo Machado (2002) a proposta de implantação foi direcionada para três áreas de conhecimento: orçamento público, gestão de custos e contabilidade governamental, assim ressaltando três pontos importantes: as classificações orçamentárias como base para a definição dos objetos de custos; o conceito de despesas orçamentárias liquidadas como elo entre a contabilidade governamental e o sistema de custos; e a aplicação do método de custeio direto para estabelecer o relacionamento entre os objetos de custos e recursos consumidos.

Apresenta três argumentos que fundamentam a sua proposta, assim: 1) Não contém qualquer tipo de rateio, permitindo assim analisar o desempenho das políticas públicas e dos gestores com maior objetividade e sem as discussões a respeito dos custos gerais transferidos. Tornando assim o objetivo central do sistema integrado de custos; 2) Esse método estão relacionado no sistema de planejamento/orçamento e contabilização da execução orçamentária, o que auxilia a implantação do sistema integrado de custos; e 3) Relação de custo-benefício da informação, embora difícil de ser quantificada, é claramente favorável ao método do custeio direto, visto que sua implantação pode ser feita muito rapidamente e com baixo custo de treinamento, já que aos gestores e funcionários esse método aparenta ser familiar.

\section{Quadro 2 - Vantagens e Desvantagens do Custeio Direto ou Variável.}

\begin{tabular}{|c|c|}
\hline VANTAGENS & DESVANTAGENS \\
\hline $\begin{array}{l}\text { - Os custos dos produtos são mensuráveis } \\
\text { objetivamente, pois não sofrerão processos } \\
\text { arbitrários ou subjetivos de distribuição dos custos } \\
\text { comuns. } \\
\text { - Lucro líquido não é afetado por mudanças de } \\
\text { aumento ou diminuição de inventários. } \\
\text { - Os dados necessários para a análise das relações } \\
\text { custo-volume-lucro são rapidamente obtidos do } \\
\text { sistema de informação contábil. } \\
\text { - É mais fácil para os gerentes industriais entender } \\
\text { o custeamento dos produtos sob o custeio direto, } \\
\text { pois os dados são próximos da fábrica e de sua } \\
\text { responsabilidade, possibilitando a correta } \\
\text { avaliação de desempenho setorial. } \\
\text { - O custeamento direto é totalmente integrado com } \\
\text { o custo-padrão e o orçamento flexível, } \\
\text { possibilitando o correto controle de custo. } \\
\text { - Impede que aumentos de produção que não } \\
\text { correspondam a aumento de vendas distorçam o } \\
\text { resultado: como os custos fixos são abatidos } \\
\text { diretamente do resultado no custeio variável, o } \\
\text { aumento de produção desvinculado do aumento de } \\
\text { vendas não provoca alteração no lucro líquido da } \\
\text { empresa. } \\
\text { - É uma ferramenta melhor para a tomada de } \\
\text { decisões dos administradores. } \\
\text { - O uso de custeio por absorção pode induzir a } \\
\text { decisões errôneas sobre a produção. }\end{array}$ & $\begin{array}{l}\text { - A exclusão dos custos fixos indiretos para valoração dos } \\
\text { estoques causa a sua subavaliação, fere os princípios contábeis e } \\
\text { altera o resultado do período. } \\
\text { - Na prática, a separação de custo fixos e variáveis não é tão clara } \\
\text { como parece, pois existem custos, semivariáveis e semifixos, } \\
\text { podendo o custeamento direto incorrer em problemas } \\
\text { semelhantes de identificação dos elementos de custeio. } \\
\text { - O custeamento direto é um conceito de custeamento e análise } \\
\text { de custos para decisões de curto prazo, mas subestima os custos } \\
\text { fixos, que são ligados à capacidade de produção e de } \\
\text { planejamento de longo prazo, podendo trazer problemas de } \\
\text { continuidade para a empresa. } \\
\text { - No caso de custos mistos (custos que têm uma parcela fixa e } \\
\text { outra variável), nem sempre é possível separar objetivamente a } \\
\text { parcela fixa da parcela variável. Embora existam técnicas } \\
\text { estatísticas para efetuar tal divisão, muitas vezes ela é tão } \\
\text { arbitrária quanto o rateio dos CIF no custeio por absorção. } \\
\text { - O custeio variável não é aceito pela Auditoria Externa das } \\
\text { empresas que têm capital aberto nem pela Legislação do Imposto } \\
\text { de Renda. A razão disso é que o custeio variável fere os princípios } \\
\text { de contabilidade, em especial os princípios de realização de } \\
\text { receitas, de confrontação e da competência. Esses princípios } \\
\text { estabelecem que os custos associados aos produtos só podem ser } \\
\text { reconhecidos à medida em que estes são vendidos, já que } \\
\text { somente quando reconhecida a receita é que devem ser deduzidos } \\
\text { todos os sacrifícios necessários à sua obtenção. Como o custeio } \\
\text { variável admite que todos os custos fixos sejam deduzidos do } \\
\text { Resultado, mesmo que nem todos os produtos sejam vendidos, } \\
\text { ele violaria tais princípios. }\end{array}$ \\
\hline
\end{tabular}

FONTE: adaptado de Weil, (2005) e MARTINS e ROSA (2014)

Mauss e Souza (2008) constatam que as vantagens ressaltam especialmente a aplicação das margens de contribuição como forma de avaliação do desempenho dos administradores. Com a finalidade de cada área se responsabilizar somente com seus custos, impedindo o 
regresso de ineficiências de outras áreas. Analisando as desvantagens, este método de custeio em curto prazo limita a análise de custos, não considera os custos indiretos, e em longo prazo podem levar qualquer empresa à falência se a margem de contribuição for insuficiente para sua geração e cobertura de lucro. Motivando assim a aplicação de outros métodos de custeio, como absorção ou $\mathrm{ABC}$, pois utilizam os gastos indiretos sobre os objetos de custo, para assim possibilitar planejamentos e análises a longo prazo.

\subsubsection{Custeio por Absorção}

Para Martinez e Alves (2011) o custeio por absorção tem como principal objetivo a transferência dos custos dos centros de custos meio (administrativos) para os centros de custos finais, sendo o custo indireto o custo transferido. Assim, para ocorrer à transferência deve-se identificar os centros de custos finais e definir o critério de rateio.

Quadro 3 - Vantagens e Desvantagens do Custeio por Absorção.

\begin{tabular}{|c|c|}
\hline VANTAGENS & DESVANTAGENS \\
\hline $\begin{array}{l}\text { - Pode melhorar a utilização dos recursos, } \\
\text { absorvendo todos os custos de produção, } \\
\text { permitindo apuração do custo total de cada } \\
\text { produto; } \\
\text { - Está de acordo com os Princípios de } \\
\text { Contabilidade e as leis tributárias; } \\
\text { - Não requer a separação dos custos de } \\
\text { manufatura nos componentes fixos e variáveis; } \\
\text { - Atende efetivamente à fixação de preços de } \\
\text { venda mais reais; } \\
\text { - Só é considerada custo a parcela dos } \\
\text { materiais utilizados na produção. }\end{array}$ & $\begin{array}{l}\text { - Os custos são quase sempre distribuídos à base de critérios de } \\
\text { rateio, quase sempre existe grande grau de arbitrariedade; } \\
\text { - O custo fixo por unidade depende ainda do volume de produção; } \\
\text { pior de tudo isso, o custo de um produto pode variar em função da } \\
\text { alteração de volume de outro produto; } \\
\text { - Os custos fixos existem independentes da fabricação ou não desta } \\
\text { ou daquela unidade, e acabam presentes no mesmo montante, mesmo } \\
\text { que ocorram oscilações (dentro de certos limites). } \\
\text { - Está no aspecto gerencial, já que todos os custos deverão se } \\
\text { incorporar aos produtos, inclusive os fixos. Deve-se utilizar algum } \\
\text { critério de rateio para alocação desses custos. Assim, mesmo que o } \\
\text { critério de rateio seja o mais ideal, haverá certo grau de } \\
\text { arbitrariedade na alocação de custos. }\end{array}$ \\
\hline
\end{tabular}

Fonte: adaptado de Weil, (2005) e MARTINS e ROSA (2014),

Mauss e Souza (2008) observam que as vantagens deste método consegue ser implementado de forma mais simples, por possuir critérios e estruturas de implementação mais acessíveis do que em outros métodos mais sofisticados. Em contra partida, este método é o centro de muitas críticas, maior parte delas é por motivo básico por causa da utilização do rateio dos custos indiretos, demonstra que isso pode adulterar informações de custo nos serviços, acrescentando de forma inadequada determinado custo em prejuízo da diminuição demais do outro, seria isso a transferência inadequada de custos.

\subsubsection{Custeio por Atividade (ABC)}

Para Luque et al (2008) o método de custeio ABC tem como fundamento a utilização dos direcionadores de custos, o que lhe permite atribuir e identificar os custos diretos e promover o rateio dos custos indiretos de forma mais objetiva, assim tornando esse método o mais recomendado para o setor público.

Quadro 4 - Vantagens e Desvantagens do Custeio por Atividade (ABC).

\begin{tabular}{|c|c|}
\hline VANTAGENS & DESVANTAGENS \\
\hline $\begin{array}{l}\text { - Proporciona melhor visualização dos fluxos de } \\
\text { processos; } \\
\text { - Identifica os produtos e clientes mais lucrativos; } \\
\text { - Eliminam/reduzem atividades que não agregam aos } \\
\text { produtos um valor percebido pelo cliente; }\end{array}$ & $\begin{array}{l}\text { - Gastos elevados para implantação; } \\
\text { - Alto nível de controles internos a serem implantados e } \\
\text { avaliados; } \\
\text { - Leva em consideração muitos dados com informações de } \\
\text { difícil extração; }\end{array}$ \\
\hline
\end{tabular}


\begin{tabular}{|l|l|} 
- Melhoram significativamente sua base de informações & - Dificuldade de envolvimento e comprometimento dos \\
para tomada de decisões; & empregados da empresa; \\
- Geram informações gerenciais relativamente mais & - Não é aceita pelo fisco, gerando a necessidade de possuir \\
fidedignas por meio de redução do rateio; & dois sistemas de custeio; \\
- Identifica o custo de cada atividade em relação aos & - Alto nível de controles internos a serem implantados e \\
custos totais da entidade; & avaliados; \\
- Pode ser empregado em diversos tipos de empresas & - Necessidade de revisão constante; \\
(industriais, comerciais, de serviços, com ou sem fins & - Necessidade de reorganização da empresa antes de sua \\
lucrativos). & $\begin{array}{l}\text { implantação; } \\
\text { - Necessidade de formulação de procedimentos padrões. }\end{array}$ \\
\hline
\end{tabular}

FONTE: adaptado de Weil, (2005) e MARTINS e ROSA (2014),

Mauss e Souza (2008) observam que as vantagens deste método consegue seguir de modo racional de custos, reconhecendo suas atividades geradores, e recolhendo de cada centro de custo todos os custos que podem ser distribuídos a eles. E as desvantagens deste método é a sua complexidade de implantação e manutenção, um dos motivos é a utilização de softwares ineficientes e falta de conhecimento do método no sistema de custo.

\subsection{Pesquisas Similares ou Correlatas}

Fez-se um levantamento no qual encontrou estudos de hospitais, de empresas públicas de países e bancos Rothschild (1971); Noreen e Soderstrom, (1997); Peter (2001); Harris e Carapiet, (2006); Banker, Fang e Mehta, M (2012); Porporato e Werbin (2012); Banker, byzalov, Chen (2013); Banker, Byzalov e Plehn-Dujowich, (2014); Novák e Vencálek (2016), mas só a pesquisa Martins e Rosa (2014) é que se aproximou do que evidencia na presente pesquisa.

A pesquisa realizada por Martins e Rosa (2014) teve como objetivo verificar a contribuição dos métodos de custeio para o processo de tomada de decisão no Corpo de Bombeiro Militar do Maranhão. Os resultados encontrados constata que cada método testado tem sua contribuição, sendo que o método de custeio padrão deve ser utilizado para fins de planejamento, na elaboração do orçamento, e os métodos de custeio direto, absorção e ABC tem sua contribuição na apuração dos custos após a execução do orçamento, cada um com suas particularidades e níveis de detalhamento de informações. $\mathrm{O}$ autor apresenta o método de absorção como o mais adequado para a administração pública por sua capacidade de gerar informações que podem subsidiar os gestores no processo de tomada de decisão.

O estudo de Carmo e Silva (2011) é verificar se o método de ABC é adequado para ser aplicado na mensuração dos custos educacionais no Colégio Militar do Rio de Janeiro. Tendo como resultado é adequado à aplicação de $\mathrm{ABC}$ para evidenciação dos custos das atividades educacionais, bem como subsidiar a avaliação da qualidade do gasto Público.

\section{Materiais e Métodos}

A presente seção abordar-se-á o enquadramento e objeto de intervenção.

\subsection{Enquadramento}

A metodologia agregada nesta pesquisa é o estudo analítico e descritivo que tem como sua principal finalidade esclarecer e desenvolver ideias, tendo como fonte de pesquisa a revisão bibliográfica e o estudo de caso.

Desta forma, o estudo de caso descritivo, inicia com a identificação e conhecimento das técnicas, atualmente, agregados a essa Organização Pública (PMSC), na gestão dos recursos 
financeiros disponibilizados, permitindo, assim, realizar um estudo aprofundado em uma circunstância real, destacando as características e especialidades da atividade desenvolvida.

Gil (2008) ressalta que a pesquisa descritiva tem como objetivo principal a descrição das características de determinada população ou fenômeno. Destacam aquelas que têm por objetivo estudar as características de um grupo, como por exemplo, órgãos públicos, assim a característica desta pesquisa é buscar identificar alguns métodos de custeio para a tomada de decisão na administração pública.

Martins (2008) a pesquisa documental é fundamental para compreender melhor o caso e também para comprovar as evidências coletadas por outras fontes e outros instrumentos, proporcionando a credibilidade de dados e de resultados achados.

Para Flick (2009) a pesquisa qualitativa usa o texto como material empírico, tendo como noção a construção social das práticas estudadas, com objetivo no entendimento dos participantes, em suas práticas do dia a dia e em seu conhecimento cotidiano relacionado à questão em estudo.

Segundo Gil (2008) o estudo de caso é caracterizado pelo estudo profundo, de modo a conceder o seu conhecimento detalhado e amplo, tarefa quase impossível diante de outros tipos de delimitações considerados.

A técnica de coleta de dados denominado é a pesquisa documental, acessando o site da Transparência do Estado de Santa Catarina (www.transparencia.sc.gov.br/despesa em março à junho de 2017) filtrando a pesquisa por Fundo de Melhoria da Polícia Militar, assim tendo acesso detalhadamente dos programas, categorias econômicas, os elementos e subelementos da unidade analisada.

Tabulando os dados na planilha de Excel permitindo inserir e montar contextos conforme a necessidade, de forma eficiente e compreensível entendimento. A partir dos contextos são realizados os cálculos de custos e o resultado final é o custo unitário utilizado em cada ocorrência.

\subsection{Caso da Polícia Militar de Santa Catarina (PMSC)}

A Polícia Militar de Santa Catarina é uma Organização Militar e tem por missão proteger e servir a sociedade, percebendo assim o número total de ocorrências atendidas nos últimos três anos e sete meses foi de 2.869.464 (em 2014: 608.130; 2015: 796.666; 2016: 902.609; e ate julho de 2017: 562.059). Desde ocorrências de nível baixo, como som alto, até de nível grave, como disparo de arma de fogo.

Convém lembrar ainda que a PMSC possui 53\% (média dos três anos analisados) do orçamento das despesas (ações) com segurança pública.

A escolha da PMSC para o estudo de caso deveu-se ao fato desta organização militar ter como atividade principal a prestação de serviços à população, e haver pouca pesquisa sobre o método de custo nesta área.

\section{Descrição e análise dos resultados}

\subsection{Apresentação dos dados}

A Tabela 1 demonstra a apuração dos custos da PMSC referente ao exercício dos anos de 2014, 2015, 2016 e até julho de 2017, mediante a utilização do método de custeio padrão. 
Tabela 1 - Apuração do Método de Custo Padrão da PMSC dos anos de 2014, 2015, 2016 e até julho de 2017.

\begin{tabular}{|c|c|c|c|c|}
\hline \multirow{2}{*}{ Bens ofertados ou serviços prestados } & \multicolumn{4}{|c|}{ VALORES LIQUIDADOS } \\
\hline & 2014 & 2015 & 2016 & $07 / 2017$ \\
\hline Conservação e Segurança Rodoviária & $5.488 .866,31$ & $4.257 .842,96$ & $6.080 .925,03$ & $2.914 .977,31$ \\
\hline Santa Catarina Rural & $28.370,28$ & $148.944,01$ & - & - \\
\hline Desenvolvimento Ambiental Sustentável & $1.990 .883,11$ & $3.753 .320,52$ & - & - \\
\hline $\begin{array}{l}\text { Modernização e Integração da } \\
\text { Inteligência e Gestão do Conhecimento } \\
\text { em Segurança Pública }\end{array}$ & - & $41.475,00$ & - & - \\
\hline Segurança Cidadã & - & - & $278.150,00$ & $25.949,00$ \\
\hline De Olho no Crime & - & - & $1.281 .426 .029,26$ & $774.147 .119,26$ \\
\hline Suporte Institucional Integrado & - & - & $67.747 .519,11$ & $35.531 .304,39$ \\
\hline $\begin{array}{l}\text { Valorização do Servidor - Segurança } \\
\text { Pública }\end{array}$ & - & - & $1.065 .579,92$ & $1.078 .541,27$ \\
\hline $\begin{array}{l}\text { Formação e Qualificação dos } \\
\text { Profissionais da Segurança Pública }\end{array}$ & $171.608,00$ & $13.625,00$ & - & - \\
\hline $\begin{array}{l}\text { Reequipamento e Apoio Operacional da } \\
\text { Segurança Pública }\end{array}$ & $69.253 .561,70$ & $60.568 .447,01$ & - & - \\
\hline Santa Catarina Segura & $10.932 .218,28$ & $8.489 .081,64$ & - & - \\
\hline Gestão de Pessoas & $1.032 .924 .316,65$ & $1.164 .416 .192,63$ & - & - \\
\hline $\begin{array}{l}\text { Gestão Administrativa - Poder } \\
\text { Executivo }\end{array}$ & $14.608 .741,68$ & $16.555 .150,61$ & - & - \\
\hline Custo Padrão & 1.135.398.566,01 & 1.258.244.079,38 & 1.356.598.203,32 & 813.697.891,23 \\
\hline Total de Ocorrências & 608.130 & 796.666 & 902.609 & 562.059 \\
\hline Custo Unitário & 1867,03 & 1579,39 & 1502,97 & 1447,71 \\
\hline
\end{tabular}

FONTE: Dados da pesquisa (2017).

Conforme os dados da Tabela 1 referente aos três anos e sete meses (do ano 2017) analisados pode-se perceber uma realocação de programas de acordo com a mudança de comandante no setor orçamentário. No decorrer dos anos o custo unitário foi diminuindo gradativamente, mesmo com a pequena base que temos em relação a 2017 por ser de um curto período. Verificando a diferença entre os anos, diminuiu em 15,41\% de 2014 para 2015, e em $4,84 \%$ de 2015 para 2016. Somando uma diminuição de $19,50 \%$ do primeiro (2014) para o último ano (2016). Analisando até Julho de 2017, houve uma diminuição em 3,68\% de 2016 para 07/2017.

A Tabela 2 demonstra a apuração dos custos da PMSC referente ao exercício dos anos de 2014, 2015, 2016 e até julho de 2017, mediante a utilização do método de custeio direto.

Tabela 2 - Apuração do Método de Custo Direto da PMSC dos anos de 2014, 2015, 2016 e até julho de 2017.

\begin{tabular}{c|c|c|c|c|c}
\hline \multirow{2}{*}{ CÓDIGO } & \multirow{2}{*}{$\begin{array}{c}\text { GRUPO NATUREZA } \\
\text { DESPESA }\end{array}$} & $\mathbf{2 0 1 4}$ & $\mathbf{2 0 1 5}$ & $\mathbf{2 0 1 6}$ & $\mathbf{0 7 / 2 0 1 7}$ \\
\cline { 3 - 6 } & Pessoal e Encargos Sociais & $966.352 .078,63$ & $1.028 .536 .925,09$ & $1.060 .339 .765,28$ & $635.244 .793,72$ \\
\hline 31 & Outras Despesas Correntes & $163.840 .007,93$ & $223.952 .405,23$ & $292.923 .429,43$ & $178.118 .872,57$ \\
\hline 33 & Custo Direto & $\mathbf{1 . 1 3 0 . 1 9 2 . 0 8 6 , 5 6}$ & $\mathbf{1 . 2 5 2 . 4 8 9 . 3 3 0 , 3 2}$ & $\mathbf{1 . 3 5 3 . 2 6 3 . 1 9 4 , 7 1}$ & $\mathbf{8 1 3 . 3 6 3 . 6 6 6 , 2 9}$ \\
\hline & Total de Ocorrências & 608.130 & 796.666 & 902.609 & 562.059 \\
\hline & Custo Unitário & $\mathbf{1 8 5 8 , 4 7}$ & $\mathbf{1 5 7 2 , 1 6}$ & $\mathbf{1 4 9 9 , 2 8}$ & $\mathbf{1 4 4 7 , 1 1}$ \\
\hline
\end{tabular}

Fonte: Dados da pesquisa (2017). 
De acordo com os valores da Tabela 2 verificando a diferença do custo unitário entre os anos, diminuiu em 15,41\% de 2014 para 2015, e em 4,64\% de 2015 para 2016. Somando uma diminuição de 19,33\% do primeiro (2014) para o último ano (2016). Analisando até Julho de 2017, houve uma diminuição em 3,48\% de 2016 para 07/2017.

A Tabela 3 demonstra a apuração dos custos da PMSC referente ao exercício dos anos de 2014, 2015, 2016 e até julho de 2017, mediante a utilização do método de custeio ABC.

Tabela 3 - Apuração do Método de Custeio por Absorção da PMSC dos anos de 2014, 2015, 2016 e até julho de 2017.

\begin{tabular}{c|c|c|c|c}
\hline \multirow{2}{*}{ DESPESAS } & \multicolumn{4}{|c}{ VALORES LIQUIDADOS } \\
\cline { 2 - 5 } & $\mathbf{2 0 1 4}$ & $\mathbf{2 0 1 5}$ & $\mathbf{2 0 1 6}$ & $\mathbf{0 7 / 2 0 1 7}$ \\
\hline Pessoal & $820.195 .001,65$ & $847.765 .694,99$ & $850.156 .328,70$ & $502.123 .167,99$ \\
\hline Serviço Pessoa Física & $521.509,55$ & $409.700,81$ & $355.737,63$ & $207.899,60$ \\
\hline Material de Consumo & $35.153 .470,30$ & $28.170 .449,19$ & $29.478 .424,94$ & $15.366 .722,58$ \\
\hline Serviço Pessoa Jurídica & $34.174 .281,85$ & $32.914 .390,36$ & $33.166 .970,17$ & $19.588 .696,44$ \\
\hline Diárias & $9.578 .299,29$ & $7.219 .397,87$ & $6.319 .460,49$ & $5.856 .075,50$ \\
\hline Passagens & $257.569,08$ & $142.264,56$ & $81.749,65$ & $87.839,85$ \\
\hline Despesas de Exercícios & $2.988 .750,49$ & $3.562 .433,27$ & $3.152 .928,11$ & $2.132 .784,63$ \\
\hline Indenização & 0,00 & $63.161 .690,77$ & $124.378 .387,58$ & $74.846 .906,08$ \\
\hline Custo Total & $\mathbf{9 0 2 . 8 6 8 . 8 8 2 , 2 1}$ & $\mathbf{9 8 3 . 3 4 6 . 0 2 1 , 8 2}$ & $\mathbf{1 . 0 4 7 . 0 8 9 . 9 8 7 , 2 7}$ & $\mathbf{6 2 0 . 2 1 0 . 0 9 2 , 6 7}$ \\
\hline Total de Ocorrências & 608.130 & 796.666 & 902.609 & 562.059 \\
\hline Custo Unitário & $\mathbf{1 . 4 8 4 , 6 6}$ & $\mathbf{1 . 2 3 4 , 3 3}$ & $\mathbf{1 . 1 6 0 , 0 7}$ & $\mathbf{1 . 1 0 3 , 4 6}$ \\
\hline
\end{tabular}

FONTE: Dados da pesquisa (2017).

Segundo os dados da Tabela 3 pode-se perceber que no decorrer dos anos o custo unitário foi diminuindo gradativamente, em relação aos gastos com pessoal e encargos e despesas correntes, mas observando a ultima coluna que se refere até julho/2017 percebe-se que ficou próximo do valor unitário do ano de 2016 , com 4,88\% de diferença, conseguindo deduzir que no final do ano de 2017 haverá um aumento.

Verificando a diferença entre os anos, diminuiu em 16,86\% de 2014 para 2015, e em $6,02 \%$ de 2015 para 2016. Somando uma diminuição de $21,86 \%$ do primeiro (2014) para o último ano (2016). Analisando até Julho de 2017, houve uma diminuição em 4,88\% de 2016 para 07/2017.

Ressalta-se que não foi reapresentando a Tabela 4. do método de custeio por $\mathrm{ABC}$, pois ao valores bases são os mesmo da tabela 3 do método de custeio por absorção.

\subsection{Analise dos dados}

Os resultados encontrados mostram-se que mesmo que seus custos totais e seus bens e/ou serviços (ocorrências) vem aumentando gradativamente, o seu custo unitário por total de ocorrências anuais no Estado de Santa Catarina vem diminuindo, assim pode-se analisar o custo-benefício que vem apropriando a organização. Deparando com o método de custeio padrão no qual determina a quantidade de recursos que foi utilizado na produção de um determinado número de bens e/ou serviços proporcionando o reconhecimento dos custos totais e unitários.

O sistema de informação de custos no setor público, ao executar o processo de accountability, melhora a transparência, pois proporciona que o conjunto da sociedade compreenda com maior clareza a utilização dos recursos públicos. Assim, com o melhoramento desse processo é indispensavelmente levado ao avanço das ferramentas à disposição dos gestores dos recursos públicos, contribuindo com o processo de tomada de decisão. 
A contabilidade pública vem passando por tempos de transformações conceituais e de posicionamento. Essas mudanças não ocorrem apenas com o objetivo de administrar o patrimônio púbico, mas também de ser um instrumento de trabalho do administrador, proporcionando informações que possa cada vez mais conceituar nas tomadas de decisões diante da sociedade.

No método de custeio direto aperfeiçoa os custos da organização de forma integrada, não mostrando os custos dos produtos de forma detalhada, auxiliando somente para a execução da disposição legal de apurar custos, considerando-se que não gera informações que ampare as tomadas de decisão por parte dos administradores.

$\mathrm{O}$ método de custeio por $\mathrm{ABC}$ tem função acessível na administração pública, e habilidade de gerar informações dos custos das atividades desenvolvidas, no entanto, ressaltouse que os valores bases são os mesmo do método de custeio por absorção.

Desta forma, verifica-se que o melhor método de custeio para este órgão pública é o de absorção, pois identifica os custos de cada bem ou serviço produzido pela organização e tem o melhor custo-benefício, isto é, pouco custoso com relação aos demais e como é uma organização de grande porte necessita saber detalhadamente de onde vêm os determinados custos.

Referente a pesquisa de Martins e Rosa (2014) há em comum a perspectiva de entender o sistema de custos, apresentando os métodos de custeio que podem ser utilizados no órgão público, verificar a contribuição desses métodos para apoiar a tomada de decisão e as suas principais diferenças para possível determinar o método mais favorável para estas organizações. Assim, concluindo que o método de custeio por absorção é mais adequado a ser aplicado nestas organizações.

\section{Considerações finais}

Os resultados encontrados mostram que é possível aplicar os métodos de custeio na administração pública, de forma que a implantação de um sistema de custos no PMSC pode ter como referência a utilização do método de custeio padrão na elaboração do orçamento, o qual estabelecerá as metas a serem atingidas e a quantidade de recursos a ser aplicados, bem como permite estabelecer tanto o custo total quanto o custo unitário dos bens e serviços a serem prestados.

No aspecto da execução orçamentária e financeira, constatou-se que os métodos de custeio direto, absorção e ABC são aplicáveis no orçamento executado, o qual permite a apuração dos custos tanto unitários quanto total, e que cada método produz um nível de informação, a qual poderá servir de base para o apoio tomada de decisão no PMSC é o custo de absorção de acordo com o resultados demonstrados na seção anterior.

Os resultados evidenciam que a apuração dos custos pelos métodos de custeio direto permite identificar a composição dos custos, destacando a formação de estruturas de estoques e o consumo deste, assim como a apropriação das despesas com depreciação/amortização. $\mathrm{O}$ método de custeio por absorção apresenta um nível mais detalhado da apuração dos custos, pois permite identificar os custos de cada bem ou serviço produzido pela organização, pois o método aloca aos bens e/ou serviços todos os custos da organização, o que o torna mais recomendado para a administração pública, considerando que esta foi criada e desenvolvida para ofertar bens e serviços à sociedade, o que faz com que todos os custos sejam alocados aos bens e/ou serviços ofertados. O método $\mathrm{ABC}$ tem fácil aplicabilidade na administração pública, e tem a capacidade de gerar informações dos custos das atividades desenvolvidas, no entanto, a administração pública é dotada de algumas atividades que são desprovidas de produtos, fato que provoca certa distorção na apuração dos custos, pois a finalidade precípua da administração pública é produzir 
bens e/ou serviços para atender as demandas sóciais, sendo de extrema importância a apuração dos custos destes bens e/ou serviços e não das atividades a serem desenvolvidas.

A presente pesquisa teve como questionamento "qual método de custeio é mais adequado para a contribuição no processo de tomada de decisão na Polícia Militar de Santa Catarina (PMSC)", com a fundamentação teórica pesquisou-se as informações necessárias de cada método de custeio e na análise dos dados evidenciou-se a aderência da fundamentação.

Por meio das análises dos dados atendeu-se o objetivo deste trabalho, verificar o método de custeio mais adequado que contribua no processo de tomada de decisão na PMSC, a análise dos resultados indicou que o método de custeio por absorção é o mais adéquo para tomada de decisão deste órgão público.

Algumas limitações neste trabalho foram às dificuldades em obter os dados da pesquisa, falta de correlação entre os setores e o acesso ao site para a busca dos dados, por ter possibilidade de encontrar apenas informações imensuráveis, e não ter literatura expressiva dos métodos de custos na área pública, então a pesquisa fez várias adaptações das organizações privadas.

Baseado neste trabalho, outros aspectos relacionados ao tema podem ser explorados em futuras pesquisas acadêmicas. Dentro do universo de estudos possíveis, recomenda-se se aprofundar em saber os custos unitários para as determinadas naturezas das ocorrências e realizar estudos com mais de um órgão por terem naturezas de recursos e atividades distintos, de forma que possa ser verificada qual a variedade no comportamento dos resultados conforme o método de custeio aplicado.

\section{Referências}

ABEL, A. B.; EBERLY, J. C. The effects of irreversibility and uncertainty on capital accumulation. Journal of Monetary Economics, v. 44, p. 339-377, 1999.

ALONSO, Marcos. Custos no serviço público. São Paulo. Revista do Serviço Público, v. 50, n.1, p. 37-63, jan./mar. 1999.

BANKER, R. D.; BYZALOV, D.; PLEHN-DUJOWICH, J. M. Demand uncertainty and cost behavior. The Accounting Review, v. 89, n. 3, p. 839-865, 2014.

BANKER, R. D.; BYZALOV, D; CHEN, L. T. Employment protection legislation, adjustment costs and cross-country differences in cost behavior. Journal of Accounting and Economics, v. 55, p. 111127, 2013.

BANKER, R. D.; FANG; MEHTA, M. Cost behavior during the world economic crisis. Working Paper, Temple University, 2012.

BRASIL. Lei Complementar $\mathbf{n}^{\circ}$ 101, de 04 de maio de 2000. Estabelece Normas de Finanças Públicas Voltadas para a Responsabilidade na Gestão Fiscal e dá outras providências.

BRASIL. Lei $\mathbf{n}^{\circ}$ 4.320, de 17 de março de 1964. Estatui Normas Gerais de Direito Financeiro para elaboração e controle dos orçamentos e balanços da União, dos Estados, dos Municípios e do Distrito Federal. Disponível em: <http://www.planalto.gov.br/ccivil_03/leis/L4320.htm>. Acesso em: 15 abr. 2017.

BRASIL. Manual de Contabilidade Aplicada ao Setor Público. 7. Ed. Disponível em: $<$ https://www.tesouro.fazenda.gov.br/documents/10180/563508/MCASP+7\%C2\%AA\%20edi 
$\% \mathrm{C} 3 \% \mathrm{~A} 7 \% \mathrm{C} 3 \% \mathrm{~A} 3 \mathrm{o}+$ Vers $\% \mathrm{C} 3 \% \mathrm{~A} 3 \mathrm{o}+$ Republica $\% \mathrm{C} 3 \% \mathrm{~A} 7 \% \mathrm{C} 3 \% \mathrm{~A} 3 \mathrm{o}+2017+06+02 . \mathrm{pdf} / 3 \mathrm{f} 7$ 9f96f-113e-40cf-bbf3-541b033b92f6>. Acesso em: 05 mar. 2017.

BRASIL. Ministério da Fazenda. Guia Rápido do SIC - Sistema de Informações de Custos do Governo Federal: Secretaria do Tesouro Nacional, 2017.

CARMO, Luis Paulo Faria; SILVA, Lino Martins. Custeio Baseado em Atividades (ABC) Aplicado ao Setor Público: Estudo de Caso no Colégio Militar do Rio de Janeiro (CMRJ). Revista UNIABEU, v. 4, n. 6, p. 161-181, 2011. Disponível em: $<$ http://www.uniabeu.edu.br/publica/index.php/RU/article/view/120/186>. Acesso em: 28 mar. 2017.

CONSElHO FEDERAL DE CONTABILIDADE. Norma Brasileira de Contabilidade Aplicada ao Setor Público: NBC TSP Estrutura Conceitual. Brasília: 2016.

FLICK, U. Desenho da pesquisa qualitativa. Porto Alegre: Artmed, 2009.

GIL, Antonio Carlos. Métodos e téenicas de pesquisa social. 6. Ed. - São Paulo: Atlas, 2008.

GRAY, D. E. Pesquisa no Mundo Real. 2. Ed. Porto Alegre: Penso, 2012.

HARRIS, H.; CARAPIET, S. The Need for Agility in Asset Management. Engineering Asset Management, p. 106-114, 2006.

KINNEY, W. R. Auditing Risk Assessment and Risk Management Processes. In Bailey, A.D. Jr. , Gramline, A.A. \& Ramamoorn, S. (Eds.) Research Opportunities in Internal Auditing. Altamonte Springs, Florida: The Institute of Internal Auditors Research Foundation. p. 131-170, 2003.

LUPORINI, V.; ALVES, J. Investimento privado: uma análise empírica para o Brasil. Economia e Sociedade, v. 19, n. 3, p. 449-475, 2010.

LUQUE, C. A.; CRUZ, H. N.; AMARAL, C. M.; BENDER, S.; SANTOS, P. M. dos. O processo orçamentário e a apuração de custos de produtos e serviços no setor público do Brasil. Revista do Serviço Público, v. 59, n. 3, p. 309-331, jul./set. 2008.

MACHADO, Nelson. Sistema de Informação de Custo: Diretrizes para integração ao orçamento público e à contabilidade governamental. Tese de Doutorado. FEA/USP, 2002.

MACHADO, Nelson; HOLANDA, Victor Branco de. Diretrizes e modelo conceitual de custos para o setor público a partir da experiência no Governo Federal do Brasil. Revista de Administração Pública, v. 44, n. 4, p. 791-820, jul./ago. 2010.

MARTINEZ, A. L.; ALVES FILHO, E. M. Requisitos funcionais de um sistema de informações para a gestão de custos no setor público. Revista Administração FACES Journal, v. 11, n.2, p. 79-99, abr./jun. 2011.

MARTINS, Jose Augusto Sousa; ROSA, Fabricia Silva da. Gestão de Custos na Administração Pública: Um Estudo de Caso no Corpo de Bombeiros Militar do Maranhão. ANAISCBC, 2014. Disponível em: $<$ https://anaiscbc.emnuvens.com.br/anais/article/viewFile/3787/3788>. Acesso em: 28 mar. 2017. 
MATIAS-PEREIRA, J. Administração pública comparada: uma avaliação das reformas administrativas do Brasil, EUA, e União Européia. Revista de Administração Pública, v. 42, n. 1, p. 62-82, jan./fev. 2008.

MAUSS, C. V.; SOUZA, M. A. de. Gestão de custos aplicado ao setor público: modelo para mensuração e análise da eficiência e eficácia governamental. São Paulo: Atlas, 2008.

NOREEN, E.; SODERSTROM, N. The accuracy of proportional cost models: evidence from hospital service departments. Rewiew of Accounting Studies, v. 2, p. 89-114, 1997.

NOVÁK, P.; VENCÁLEK, O. Is It Sufficient to Assess Cost Behavior Merely by Volume of Production? Cost behavior research results from Czech Republic. Montenegrin Journal of Economics, v. 12, n. 3, p. 139-154, 2016.

PETER, Maria da Glória Arrais. Proposta de um Sistema de Custos para as Univerdidades Federais Brasileiras Fundamentado no Activitu Based Costing: uma abordagem de controladoria estratégica. Dissertação de Mestrado. FEA/USP, 2001.

PLATT NETO, O. A. Contabilidade Pública: atualizada e focada. Livro didático da Disciplina Contabilidade Pública II do Curso de Graduação em Ciências Contábeis da Universidade Federal de Santa Catarina (UFSC). 18. ed. (rev. e atual. - semestre 2017/2). Florianópolis: Edição do autor, 2017.

PORPORATO, M.; WERBIN, E. Active cost management in banks: Evidence of sticky costs in banks of Argentina, Brazil and Canada. 66

ROTHSCHILD, M. On the Cost of Adjustment. The Quarterly Journal of Economics, v. 85, n. 4, p. 605-622, 1971.

SARDAR, G.; RAMACHANDRAN, N.; GOPINATH, R. Challenges in achieving optimal asset performance based on total cost of ownership, Engineering Asset Management, Springer, London, p. 54-63, 2006.

SHAHNAZARI, E.; TALEBNIA, G.; JAMEI, R. Study of adjusted profit and productivity forecast error of bazaar with using of cost behavior. Life Science Journal, v. 10, n. 1, p. 684-694, 2013.

SILVA, Lino Martins da. Problemas para o Desenho e Implantação de um Sistema de Custos na Administração Pública, o método Activity Based Costing (ABC). In: X Congresso Internacional de Custos, 2007, Anais. 13 a 15 de junho. Lyon, França.

SUBRAMANIAM, C.; WEIDENMIER, M. L. Additional evidence on the sticky behavior of costs. Social Science Research Network, 2003. Disponível em: $<$ http://ssrn.com/abstract=369941 >. Acesso em: 25 jul. 2016. 67

WEIL, R. L.; MAHER, M. Handbook of cost management, 2 ed. Hoboken, NJ: Wiley, 2005.

WEST, D. A. Three financial strategies. Journal of Health Care Finance, v. 30, n. 1, p. 10-22, 2003. XUE, S.; HONG, Y. Earnings management, corporate governance and expense stickiness. China Journal of Accounting Research, v. 9, p. 41-58, 2016. 